\title{
Parallel Stories: Teachers' Reflections on Professional Development for Roma Inclusion in the Greek-Cypriot and the Greek Educational System
}

\author{
Yiasemina Karagiorgi (Corresponding author) \\ Cyprus Pedagogical Institute \\ Latsia, Nicosia
}

Tel: 357-22-402-317 E-mail: yiasemin@logos.cy.net

\author{
Loizos Symeou \\ Department of Education Sciences, European University Cyprus \\ Nicosia, Cyprus \\ E-mail: 1.symeou@euc.ac.cy
}

Giorgos Nicolaou
University of Ioannina
Ioannina, Greece
E-mail: gnikolau@uoi.gr

Eleni Roussounidou

Ministry of Education and Culture

Nicosia, Cyprus

E-mail: releni@cytanet.com.cy

Chrystalla Kaloyirou

Cyprus Pedagogical Institute

Latsia, Nicosia

E-mail: chrykalo@spidernet.com.cy 
Received: October 12, 2011 Accepted: November 1, 2011 Published: November 15, 2011

doi:10.5296/ije.v3i2.1014 URL: http://dx.doi.org/10.5296/ije.v3i2.1014

\begin{abstract}
This comparative study discusses two teacher training programmes implemented at the Greek-Cypriot and the Greek educational systems. Both programmes were provided within the framework of the European funded project INSETRom, which aimed towards more inclusive Roma education through teacher professional development. Training modules, designed on the basis of reported teachers', parents' and children's needs, were offered concurrently in the two countries from January to May 2009. Data collected from participants before and after training indicated that the modules met teachers' expectations only to a certain extent and that participants' levels of confidence in teaching Roma, teaching about Roma and addressing stereotypes about Roma improved only slightly. Despite the diversity of responses, when compared with their Greek-Cypriot counterparts, Greek teachers appeared more satisfied with the training, probably because of their more extensive experience in teaching Roma students. Teachers' responses underline the importance of additional teacher training firstly, to enhance understanding of Roma culture and, secondly, to address practical classroom strategies. The paper discusses further contextual and methodological directions for training to enable teachers to respond to multicultural classrooms. The study holds implications for the design of training for Roma inclusion in particular and intercultural education in more general.
\end{abstract}

Keywords: Teacher training, Evaluation, Roma, Cyprus, Greece 


\section{Introduction}

Against the background of insufficient participation, unequal access, and barriers faced by Roma in education, teacher in-service training often holds the potential to foster inclusion and equity. On these grounds, two parallel teacher training programmes on Roma education were designed and offered in the Greek-Cypriot and the Greek educational systems, within the framework of the European funded project INSETRom (IN-SErvice Training for Roma Inclusion, 134018-LLP-1-2007-1-CY-COMENIUS-CMP). To counterbalance possible disadvantages of mass in-service training that can be cost-effective but irrelevant to teachers' practice, these programmes were offered on the basis of diagnosed teachers' professional development needs. To provide for an evaluation of these programmes from participants' perspective, pre- and post- training questionnaires were designed and distributed to the participating teachers in the two countries. The present study outlines the outcomes of this evaluation in the two settings and attempts comparisons across them to highlight certain trends in teachers' perceptions, so as to draw repercussions for the design and implementation of similar programmes not only within the particular national contexts but elsewhere, as well. At the same time, the study escapes from a purely comparative approach, deemed inappropriate due to the variations involved in tailoring the content and structure of each one of the two training programmes to teachers' needs.

\section{The Context}

\subsection{Roma in Cyprus}

Roma (Cigani or Tsiggani) are one of the smallest minorities living in Cyprus that more possibly arrived to Cyprus in the 14th century as a result of Indian migration. During the eighteenth century, most Roma were Muslim Roma (Ghurbeti) while a few were Greek Orthodox Christian Roma (Mandi).

After the establishment of the Republic of Cyprus in 1960, the Roma population of Cyprus became officially part of the Turkish-Cypriot community. Although the language of Roma was closely related to the Roma of Europe and both Mandi and Ghurbeti spoke a kind of Romany-similar to English Romani (Marsh \& Strand, 2003)- the language of the youngest generation of the former is Greek and the latter Turkish. Following the 1974 Turkish invasion in Cyprus, Mandi living in the north were forcibly moved to the south and Ghurbeti to the north. After being moved, Roma settled in houses abandoned by their original owners creating new communal groupings on both sides of the demarcation line.

Approximately a decade ago, several Roma groups from the north started moving to the south and settled in socio-economically deprived areas of Limassol and Paphos. Since April 2003, when travel restrictions across the demarcation line were eased, the influx of Roma to the south increased; 570 of the 1500 Roma living in Cyprus today (UNOPS, 2004) reside in the south. Marsh and Strand (2003) argue that the real number of Roma reaches 2000-3000 people, due to the annual influx of illegal Anatolian Romanlar, but this information cannot be confirmed (Agathokleous, 2005).

Roma in Cyprus have to a large extent been ignored, avoided and kept on the margins of the 
local society (Demetriou \& Trimikliniotis, 2007; Trimikliniotis, 2007), a fact mainly attributed to the dominant perceptions about them (Iacovidou, 2009). According to recent European Commission reports on social exclusion, Roma are reported as one of the local social groups outside social networks (European Commission, 2005; Council of the European Union, 2006).

Like any other child at school age, Roma children enroll in Greek-Cypriot schools. However, Roma children's school attendance is irregular (Symeou, Karagiorgi, Roussounidou, \& Kaloyirou, 2009). Therefore, social services try to convince Roma families to urge their children to attend school, while parents are presented with various incentives, such as uniforms and school equipment (Agathokleous, 2005). As a result, the numbers of Roma pupils in Greek-Cypriot primary schools increased from 30 during 2000-2001, to 90 during 2003-2004. Enrolment of Roma children during 2008-2009 exceeded the number of 100.

Despite increased enrolment numbers, data on Roma students' attainment and drop-out rates suggest that most Roma children end up almost illiterate (Demetriou \& Trimikliniotis, 2007). Two 2003 studies showed that Roma parents saw no reason to send their children to school, as they understood nothing, they got into fights and felt excluded (Hatzitheodoulou-Loizidou \& Symeou, 2003; Trimikliniotis, 2007). Serious problems with the transition between primary and secondary school were also reported. Moreover, despite an official policy of non-segregation, it is suggested that there is a trend towards Roma segregation in schools with high concentration of migrants, minorities and Greek-Cypriots from poorer backgrounds (Demetriou \& Trimikliniotis, 2007). Seemingly positive local measures intended to desegregate Roma by dividing classes with a lot of Roma, coupled with provision of additional language classes resulted in further marginalization of Roma students, as well as racial prejudice towards the Roma.

\subsection{Roma in Greece}

Roma (or Gypsies) initially appeared in the Greek region during the Byzantine Empire and were possibly of Indian origin (Fraser, 1992, Liegeois, 1986). Their residence in Peloponnesus in combination with their dark-skinned feature led to a misunderstanding that they originated from Egypt, that is why were called "Gyfti". Roma's contact with local religions led to their Christianization and later -during the Ottoman Empire- to partial islamisation.

Nowadays there are about 230000 Roma, mostly in North Greece, Northwest and West Peloponnesus, Epirus and Etoloakarnania, as well as Thessalia (Larisa, Farsala, Sofades) and Attiki (Agia Barbara, Petralona, Xalandri, Moschato, Menidi) (Fraser, 1992; Stratiotou, 2008). According to the legislation, all Roma, as permanent residents of the country, are Greek citizens (Terzopoulou \& Georgiou, 1996; Stratiotou, 2008).

Roma differ mainly on religion and their dialect, Romani. They are either Christian Orthodox or Muslims (Gotovos, 2003; Labridis, 2004). According to the linguist Marcelo, they speak two dialects of Romani: vlach and non-vlach (Lydaki, 1998: 28). Roma deal with retail trade, seasonal works, music, dance and have abandoned traditional professions like blacksmith, 
junk or animal trader. The mastery of the professions is learned by older family, and there are no welfare programmes for the Roma (Sideri, 1993; Terzopoulou \& Georgiou, 1996; Lydaki, 1998; 2000; Vaxevanoglou, 2001; Labridis, 2004; Stratiotou, 2008).

Roma relations with education appear complex since for decades they did not have the right, at least officially, to register to schools (Ntousas, 1991: 130). The majority of Roma -especially women- were illiterate (Gotovos, 2003). Young Roma had high school failure and drop-out rates. Even though Roma parents firmly indicated their intention to send their children to school, this did not happen (Kokkinakis, 1983, Ntousas, 1991; Moucheli, 1996; Vasileiadou \& Pavli-Kore, 1998; Komis, 1998; Lydaki, 2000; Labridis, 2004; Siotou, 2004; Stratiotou, 2004). The causes of inadequate schooling related to Roma identity and culture (Komis, 1998; Moucheli, 1996). Schools and teachers were often hostile, accusing Roma of lack of hygiene, interest and motives (Dikaiou, 1990; Politou, 1996; Ntousas, 1997; Komis, 1998; Gotovos, 2004a; 2004b; 2004c; Stratiotou, 2008). Roma noted a disharmony in the fulfilment of their professional needs by Greek schools, seen as a "waste of time" and representing another culture. Schools appeared to target reading and writing (Dikaiou, 1990; Vasileiadou, 2000; Siotou, 2004; Levinson \& Sparkers, 2005). Roma bilingualism (Vasileiadou, 1998; Chalkiotis, 2000), early marriage (Politou, 1996; Ntousas, 1997), nomadic way of living (Politou, 1996; Ntousas, 1997; Levinson \& Sparkers, 2005), child labor (Politou, 1996; Katsikas \& Politou, 1999; Chalkiotis, 2000), Roma's lack of pre-school education and school's schedule (Stasinos, 2004) were also considered as factors for Roma students' drop-out rates.

Specific measures (special classes, remedial sectors, educational schedule, transporting card) did not succeed to make school attractive to Roma, as expected. Nowadays, despite the progress, the request for radical changes on education for Roma is urgent.

\subsection{Roma Education and Teachers}

The issues raised in both countries resemble common problems with Roma education worldwide, while teachers often lack sufficient knowledge and preparation to work optimally with Roma children. Trentin et al. (2006) refer to teachers' stereotypes, emotional reactions and attitudes towards Roma as well as their concerns, practical difficulties and behavioural intentions. Results of this study confirm that stereotypes are difficult to change, although direct contact can contribute to positive emotional reactions and attitudes towards Roma. In addition, teachers appear concerned about the difficulties of implementing integrated schooling and report a medium level of willingness towards the task of integration. In a study on inclusion as a process of recognising and minimising the barriers to learning, Pecek et al. (2008) ask how teachers rank different groups of marginalised children and how they regard their own role, the role of the marginalised and other children, as well as parents in the inclusion process; results show that teachers put the least trust in Roma parents.

Hence, teachers' attitudes towards Roma arise as an issue of concern as teachers need to adapt teaching methods and the curriculum to make the school more interesting for Roma children and become themselves more familiar with Roma culture and history (Kyuchukov, 2000). In this direction, teachers need to be trained and sensitized to Roma language and 
culture. In addition, while inquiring into teachers' reactions in the context of markedly increased student diversity at a Spanish school, Teasley (2005) points to the need for alternative means, such as action research, to produce professional commitments, more conducive to socially and culturally responsive educational processes.

\section{The Training}

In Cyprus three schools, attended by a number of Roma children were chosen for this study. Two of the schools, a primary and a lower secondary school, were situated in an urban area of Limassol; the third was a primary school, located in a semi-urban area in Paphos. All three schools belonged to the Zones of Educational Priority and shared similar characteristics: relatively large presence of Turkish-Cypriot, Roma and non-Greek speaking students, low socio economic composition of the region, large number of children in families and educational difficulties. In Greece the study was conducted in two primary schools, attended by Roma students in Larissa. Due to an increase in the number of Roma children over the last years, Roma students in these two schools were the majority.

In the two countries, the design and implementation of an in-service training programme for Roma Education was preceded by an initial needs assessment study (Symeou et al., 2009; Nikolaou, 2009). The main aim of the needs assessment study was to identify teachers', Roma parents' and Roma children's needs in the participant schools, thus providing the basis for the development of the in-service teacher training curriculum. Therefore, semi-structured interviews with a sample of teachers, parents and children were conducted in each country. Interviewing appeared effective as a method for data collection because it developed discussion and provided a range of responses (Cohen \& Manion, 1994; Marshall \& Rossman, 1995). Preceding data collection, rapport with the teaching staff and Roma families in the schools was established. In the case of Roma families, this appeared extremely difficult since interviewing Roma parents and children posed certain methodological concerns, as is often the case (Messing, 2008). Interviews were transcribed while interview questions comprised the framework for the qualitative analysis.

Based on the findings of the initial needs assessment, a common analytic curriculum for teacher training was designed by all partners participating in the project to enhance teachers' awareness of the Roma culture and develop teachers' skills and strategies to engage Roma parents as active agents in their children's education. The training curriculum included goals, modules and methodology and targeted curricular sections responding to each country's specific educational needs as these evolved through the needs assessment study. Consequently, the curriculum had a considerable core common to all countries, but responded to specific local needs and the existing differences within different contexts and Roma populations. Nine training modules were developed, as follows: Culture and enculturation, Stereotypes and prejudices, Roma history, Roma culture, Cultures of the schools-The arts and cultural diversity, Intercultural education, Classroom management and methodology, Curriculum development, Teacher-parent communication (see http://www.iaie.org/insetrom/1_materials_curriculum.html).

Teachers in the participant schools in Cyprus and Greece were given the titles of these 
modules to choose from. In both settings, teachers chose the following five modules: Culture and enculturation, Roma history, Roma culture, Intercultural education, and Classroom management and methodology. In addition, Creek-Cypriot teachers chose Curriculum development while Greek teachers chose Stereotypes and prejudices, as well as Teacher-parent communication.

The training sessions in the two countries were organized between February-May 2009. The training was provided by a small team of trainers in each country; two to three national experts complemented this team and provided the necessary national context and input. The choice of teams of trainers accentuated the cross-curricular character of the topic (e.g. history, citizenship, literature and school psychological issues) and created an active support network in each school. Training was attended by 17 teachers (6 male, 11 female) in Cyprus and 26 teachers (10 male, 16 female) in Greece. Five afternoon meetings of three hours each took place at one of the schools in Cyprus against four whole day meetings of seven hours each at one of the schools in Greece. Consequently, the duration of the training programme ranged from 15 hours in Cyprus to 28 hours in Greece.

\section{Research Questions}

In this study primarily, interest was placed on exploring what participants thought of and felt about the training provided. Secondarily, it became important to explore the extent to which trainees' levels of confidence in teaching Roma, teaching about Roma and addressing stereotypes about Roma changed after the training. Hence, two research questions were stated as follows: (1) What were teachers' reactions to the training? (2) What were teachers' perceived learning outcomes, with regards to their levels of confidence in approaching Roma students? A third research question 'Which were teachers' future concerns with regards to Roma education?' was added to reveal teachers' perspectives on the development of educational practices related to Roma children in Greek-Cypriot and Greek schools respectively.

\section{The Study}

As already pointed in the Introduction, the data presented in this paper was collected through questionnaires before and after the training. The questionnaires aimed to collect teachers' insights on the strengths, weaknesses and barriers of the offered training, along with their perceptions on levels of confidence in approaching Roma students.

In specific, the pre-training questionnaires included questions on teachers' teaching background (age of their pupils, subject matter, experience in teaching in classes with Roma children), as well as experience on Roma education (e.g. levels of training to teach Roma children or Roma issues); levels of confidence to teach Roma children and Roma issues and to address stereotypes and prejudices towards Roma in the classroom; relations between Roma and other children; relations of teachers with Roma parents; teachers' challenges when teaching Roma children and Roma issues in the classroom; training necessary to help teachers deal with Roma students or Roma issues; adequacy of teaching materials regarding Roma history; suggestions and comments. 
The post-training questionnaire addressed participants' views on training aspects, such as the content, the presentation, the training methodology, the duration and the trainers. This questionnaire asked teachers to indicate the training modules they considered most and least valuable or useful. Furthermore, teachers were asked to indicate the extent to which training met their expectations, as well as their levels of confidence teaching Roma students, teaching Roma issues and addressing stereotypes. Finally, teachers were asked to indicate the strategies they intended to use after the training, along with possible barriers in implementing ideas resulting from the training programme.

Questionnaires in Cyprus were returned by 14 out of the 17 trainees and in Greece by 25 out of the 26 participating teachers. These teachers taught more than one subjects to children from 6 to 12 years old. All respondents noted that they taught Roma children, although the percentage of Roma children in their classes ranged from 15\% to 75\% for Greek-Cypriot and $6 \%$ to $100 \%$ for Greek teachers. Respondents varied in years of teaching with Greek-Cypriot and Greek teachers ranging from 3 to 32 years and from 5 to 24 years, respectively.

The data analysis aimed at describing the demographic characteristics of the teachers at each country, and at identifying the frequency for each topic-item of the questionnaires. Descriptive statistics (frequencies and percentages) were used to report on the separate topic-items in order to identify teachers' views in each country. Inferential statistics- even though possible- were not conducted due to the small number of respondents in each country.

\section{Research Outcomes}

\subsection{Training Background}

Greek teachers appeared to be better trained compared to their Greek-Cypriot colleagues; hence, the majority of the later described themselves as 'not well trained' to teach classes with Roma children (Table 1). 'Somewhat well trained' Greek-Cypriot teachers referred to their own initiatives to prepare for teaching in classes with culturally diverse populations ("After 5 years of dealing with them, I now feel confident that I can make it"). On the contrary, most Greek teachers appeared to be 'very well' or 'somewhat well' trained, which could be attributed to their long experience with Roma. Interestingly, eleven Greek teachers indicated that they lacked training.

Similar was the teachers' evaluation of their ability to teach about Roma issues, such as Roma culture and history. Again, the two 'somewhat trained' Greek-Cypriot teachers referred to their personal initiatives to become more knowledgeable about Roma and their acquired daily experiences with Roma children through the years. In the case of Greek teachers, the situation appeared slightly different, although again the majority of teachers -more than half- described themselves as 'not well trained'.

In both contexts, teachers underlined the need for further training on Roma history and culture "so that we [they] do not make any mistakes in approaching Roma children". They also asked for more practical training on appropriate methodologies "to teach language and mathematics to these children", and "to handle these children". Finally, they indicated the need for school teaching material, curriculum and textbooks to enhance Roma children 
motivation and commitment and make Roma "happy in school".

Table 1. Participants' training background

\begin{tabular}{|c|r|r|r|}
\hline \multicolumn{2}{|c|}{ CYPRUS } & \multicolumn{3}{|c|}{ GREECE } \\
\hline $\mathrm{N}$ & $\%$ & $\mathrm{~N}$ & $\%$ \\
\hline
\end{tabular}

If you teach Roma/Gypsy/Traveller children, how well trained do you feel you were in the past to teach these children?

\begin{tabular}{|l|r|r|r|r|}
\hline Very well trained & 0 & 0 & 6 & $24 \%$ \\
\hline Somewhat well trained & 2 & $17 \%$ & 8 & $32 \%$ \\
\hline Not well trained & 8 & $67 \%$ & 10 & $40 \%$ \\
\hline Not at all well trained & 2 & $17 \%$ & 1 & $4 \%$ \\
\hline
\end{tabular}

How well trained do you feel you were in the past to teach about Roma/Gypsy/Traveller issues (relating for instance to culture and history)?

\begin{tabular}{|l|r|r|r|r|}
\hline Very well trained & 0 & 0 & 1 & $4 \%$ \\
\hline Somewhat well trained & 2 & $14 \%$ & 8 & $32 \%$ \\
\hline Not well trained & 1 & $7 \%$ & 13 & $52 \%$ \\
\hline Not at all well trained & 11 & $79 \%$ & 3 & $12 \%$ \\
\hline
\end{tabular}

\subsection{Teachers' Reactions: Overall Training Evaluation}

Table 2. Teachers' expectations

\begin{tabular}{|l|l|}
\hline CYPRUS & GREECE \\
\hline $\mathrm{N}$ & $\mathrm{N}$ \\
\hline
\end{tabular}

To what extent do you feel your expectations of the training have been met?

\begin{tabular}{|l|l|l|}
\hline Fully & 0 & 12 \\
\hline Average & 4 & 13 \\
\hline Poorly & 6 & 1 \\
\hline Not at all & 4 & 0 \\
\hline I found this training: & \multicolumn{2}{|l|}{} \\
\hline Not interesting at all & 5 & 0 \\
\hline Average & 7 & 0 \\
\hline Interesting & 2 & 6 \\
\hline Challenging/stimulating/ very interesting /learned new things & 0 & 20 \\
\hline
\end{tabular}

The training did not appear to fully meet Greek-Cypriot teachers' expectations (Table 2). In particular, only four teachers said that their expectations were met to 'an average' extent while the rest (ten participants) indicated either 'poorly' or 'not at all'. Consequently, most Greek-Cypriot teachers described the training as 'not interesting' or 'average'. On the contrary, their Greek colleagues appeared quite satisfied from the programme, pointing that their expectations were met either 'fully' or to 'an average' extent and finding the training as either 'interesting' or 'very interesting'. When asked which of their expectations were not met during the training, Greek-Cypriot and Greek trainees referred to not receiving enough practical suggestions on how to teach Roma children. 


\section{Macrothink}

As expected, most Greek-Cypriot teachers thought of the training aspects as either 'good' or 'poor' while their Greek counterparts thought of them as either 'excellent' or 'good' (Table 3).

Table 3. Evaluation of training aspects

\begin{tabular}{|c|c|c|c|c|c|c|c|c|c|}
\hline \multirow{2}{*}{$\begin{array}{l}\text { Please circle the number that best represents your } \\
\text { assessment of the following aspects of the training }\end{array}$} & \multicolumn{4}{|c|}{ CYPRUS } & \multicolumn{5}{|c|}{ GREECE } \\
\hline & 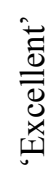 & $\bar{z}_{0}$ & $\begin{array}{l}\dot{0} \\
\dot{0}\end{array}$ & $\tilde{z}_{\tilde{E}}^{\tilde{q}}$ & 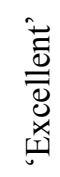 & $\dot{\bar{g}}^{2}$ & $\stackrel{\dot{0}}{\circ}$ & $\ddot{\tilde{m}}$ & $\begin{array}{l}\dot{0} \\
\sum_{0}^{0} \\
\dot{0} \\
0 \\
z\end{array}$ \\
\hline Coverage of content & 0 & 4 & 7 & 3 & 14 & 10 & 1 & 0 & 1 \\
\hline Clarity of presentations & 0 & 6 & 5 & 3 & 5 & 12 & 0 & 0 & 1 \\
\hline Training methodology & 1 & 5 & 6 & 2 & 12 & 15 & 1 & 0 & 1 \\
\hline Duration of training & 0 & 7 & 5 & 2 & 4 & 19 & 1 & 0 & 1 \\
\hline Professionalism of trainers & 0 & 5 & 6 & 3 & 1 & 4 & 0 & 0 & 1 \\
\hline
\end{tabular}

Greek-Cypriot teachers (Table 4) suggested that although the content of the training appeared appropriate, the presentations were not satisfactory. The vast majority, as indicated above, thought that the training failed to address applicable issues. As one teacher pointed, "The training programme was like 'psychotherapy' as we had a chance to express our views and concerns. However, we did not receive answers". Teachers expressed their disappointment that the training did not include enough practical ideas from other educational systems, such as material on Roma education from other European countries. They further stated that the material presented related more to a multicultural school environment rather than to the Roma school population, e.g.: "My expectation was to be presented a special teaching methodology and content for the needs and the special characteristics of Roma children". As another teacher clarified:

Roma are not as the rest of the children in a multicultural school. Children do not come to school with serious lack of experiences, knowledge and so forth; they just don't speak the language. This is not the case with Roma. Most of these children have also behavioral problems.

Table 4. Overall evaluation of modules and processes

How would you rate the training modules and process overall?

\begin{tabular}{|l|l|l|l|l|l|l|l|l|l|}
\hline & CY & GR & CY & GR & CY & GR & CY & GR & \\
\hline Very useful & 0 & 21 & 4 & 5 & 4 & 0 & $4 *$ & 0 & Little use \\
\hline Good discussions & 4 & 24 & 5 & 2 & 4 & 0 & 0 & 0 & Limited discussions \\
\hline Flexible structure & 2 & 14 & 2 & 12 & 8 & 0 & 2 & 0 & Rigid structure \\
\hline Well conducted & 2 & 24 & 2 & 2 & 5 & 0 & 4 & 0 & Poorly conducted \\
\hline Demanding & 2 & 4 & 4 & 20 & 3 & 2 & 5 & 0 & Undemanding \\
\hline Well spaced out & 3 & 21 & 4 & 4 & 5 & 1 & 2 & 0 & Too condensed \\
\hline Good use of time & 2 & 22 & 6 & 4 & 4 & 0 & 2 & 0 & Poor use of time \\
\hline Good level of activity & 0 & 12 & 4 & 13 & 5 & 1 & 4 & 0 & Poor level of activity \\
\hline Very practical & 0 & 12 & 0 & 14 & 5 & 0 & 9 & 0 & Not at all practical \\
\hline Very applicable & 0 & 17 & 0 & 9 & 5 & 0 & 9 & 0 & $\begin{array}{l}\text { Not at all applicable in } \\
\text { your teaching }\end{array}$ \\
\hline
\end{tabular}


Not surprisingly, after the completion of the training, both Greek-Cypriot and Greek teachers expressed their most positive evaluation for the module Roma culture and history because of its direct relation to Roma. Greek teachers also indicated a preference for the module Intercultural education and Greek-Cypriots for Curriculum (e.g. "This (module 'Curriculum') was somewhat useful"; "The most constructive module was on curriculum"). When asked which modules they found useful for their teaching, the majority of participants did not respond to this question. With regards to training processes, one teacher suggested that workshops would be preferable. In addition, participants liked the websites suggested by the trainers, which offered specific ideas that linked teaching to Roma life and culture. Teachers indicated preference for tangible, practical advice on resolving real class situations. Respectively, what teachers appeared to find more useful was practical ideas or strategies they could use in teaching in classes with Roma children. One teacher stated that he/she will try to use strategies to involve Roma families in their children's school life as follows:

In the arts lesson I will plan a session for Roma children and the rest to work in groups to create a mosaic on a topic of their own interest. Each pupil will express his/her ideas for what he/she would like to create and the artifacts will decorate a wall in the school.

In the Greek context, most participants considered all modules as useful, while three pointed against the module Teacher-parent communication. One teacher referred to Curriculum, as it was considered "too general and not related to Roma children" while teachers commented that "all modules were theoretical and not useful" and that there was "too much theory". In explaining their evaluation, both Greek and Greek-Cypriot teachers pointed that due to their gained teaching experience with Roma, the training itself could not surpass this experience: "We did not receive answers for the essential and practical problems we teachers face in dealing with and helping Roma children in specific". Teachers seemed to want more 'solutions' (“...we expected more knowledge and resources, so as to help these children").

\subsection{Teachers' Learning: Levels of Confidence}

No Greek-Cypriot teachers expressed high confidence in teaching Roma children before the training (Table 5). Both Greek-Cypriot and Greek teachers who expressed some confidence in teaching Roma, linked this again to their experience with Roma. Interestingly, after the training, Greek-Cypriot teachers expressed only slight increase in their confidence to teach Roma children; in the case of Greek teachers, levels of confidence appeared higher. Problems in considerable increase of confidence -especially in the case of Greek-Cypriot teachersappeared related to various challenges. When asked what they saw as their greatest challenge when teaching Roma children, most teachers referred to lack of Roma children's consistent school attendance and problems with their reading and writing skills. Some explained that they tried to keep Roma children alert, interested and engaged with the school programme: "Even only to make them to want to stay in the class is a huge challenge!"; "The biggest challenge is to find a way or a window to their world, so I become able to provide them with as many as I can, among those [things] that I consider useful for them." Similarly to their Greek-Cypriot colleagues, Greek teachers referred to various problems in their efforts "to 
approach their [Roma] culture"; "to make them interested in school"; "to ameliorate their school results"; "to fight against racism and stereotypes"; "to urge them to continue their studies in high school" and "to convince them (the girls) not to be married very early". Although Greek teachers expressed higher confidence upon the completion of the training, they pointed towards "more knowledge and guidance" since, as one teacher noted, they didn't "know at all how to deal with such issues in my [their] class".

With regards to levels of confidence in teaching about Roma issues, the situation appeared similar to the findings above, with Greek-Cypriot teachers indicating minimal changes in their confidence -which remained low- after the training. Greek teachers also confirmed their lack of confidence in teaching Roma culture and history; however, this group's level of confidence appeared to improve significantly after the training. When asked about their greatest challenge when teaching about Roma issues, most teachers stated they had never taught Roma culture and history. In explaining why, some pointed that they had to learn about Roma culture themselves first; as one teacher explained, "I might-unintentionally- transmit some stereotypes for Roma -wrong ones- to my pupils". Others mentioned that many Roma pupils did not identify themselves as Roma, which complicated things even further.

Table 5. Teacher confidence (before and after the training)

\begin{tabular}{|c|c|c|c|c|}
\hline \multirow[t]{2}{*}{ How confident do you feel to } & \multicolumn{2}{|c|}{ CYPRUS } & \multicolumn{2}{|c|}{ GREECE } \\
\hline & Before & After & Before & After \\
\hline \multicolumn{5}{|l|}{ teach Roma children? } \\
\hline Very confident & 0 & 1 & 6 & 15 \\
\hline Somewhat confident & 6 & 5 & 10 & 11 \\
\hline Not very confident & 6 & 7 & 8 & 0 \\
\hline Not at all confident & 2 & 1 & 1 & 0 \\
\hline \multicolumn{5}{|c|}{ teach your pupils about Roma issues? } \\
\hline Very confident & 0 & 1 & 0 & 17 \\
\hline Somewhat confident & 2 & 2 & 14 & 9 \\
\hline Not very confident & 5 & 7 & 9 & 0 \\
\hline Not at all confident & 7 & 4 & 2 & 0 \\
\hline \multicolumn{5}{|c|}{ address any existing stereotypes and prejudices towards Roma in the classroom? } \\
\hline Very confident & 1 & 1 & 3 & 12 \\
\hline Somewhat confident & 4 & 4 & 13 & 14 \\
\hline Not very confident & 4 & 4 & 6 & 0 \\
\hline Not at all confident & 5 & 5 & 3 & 0 \\
\hline
\end{tabular}

Both Greek-Cypriot and Greek teachers' statements of confidence in addressing existing stereotypes and prejudices towards Roma in their classes appeared more positive, compared to their responses to the previous two statements. Similarly, upon completion of the training, Greek-Cypriot teachers' evaluation of their confidence in addressing existing stereotypes and prejudices towards Roma was not greatly improved; teachers expressed exactly the same degree of confidence as prior to the training. Once again, most teachers stated that they did not feel to "have changed compared to before the training". In particular, one teacher noted: 
"I have to handle my own prejudices first and then teach Roma pupils and other pupils to face their prejudices against Roma". Those who reported some confidence in addressing stereotypes related this to their overall confidence in dealing with prejudices towards children from different cultural groups. The results were different again in the case of Greek teachers who appeared to be either 'very confident' or 'somewhat confident' after the training.

\subsection{Future concerns}

In both countries, teachers predicted that they will continue to face difficulties in teaching Roma children. They suggested that Roma children will keep having a lot of absences from school and will continue to accumulate learning difficulties and resist to collaboration. Despite some positive gains from the training, Greek-Cypriot teachers appeared mainly pessimistic about the impact of the training to their teaching. This disappointment was reflected in several comments: "I will continue to resolve problems that might relate to the strategies I use or will use from those I gained from this training as I did always: through practice and experience; trial and error"; "I will continue to handle such problems in my standard way, with understanding and patience".

In both settings, teachers commented that they would like training to be more focused on specialized knowledge and strategies for dealing with Roma populations. Practicality also emerged as an issue of concern. Towards this direction, Greek-Cypriot respondents suggested the organization of workshops and the attendance of lessons in classrooms with Roma. Greek teachers recommended teaching methods appropriate for Roma, information about the laws for Roma, ways to resolve problems in the classroom with Roma and crisis management.

At the same time, several teachers complained about the lack of school material for teaching Roma children. As they explained, such material was often a product of the work the teachers themselves prepared or re-organised from existing material on other cultural groups or cases ("It is absolutely necessary to create teaching material for language and mathematics immediately. This material should correspond to the interests and the way Roma children think and act"). Four Greek teachers further suggested the integration of the Roma pupils in the Greek society as problematic. As one teacher underlined, "The biggest challenge for the Roma is to be invited to the party of the other pupils".

\section{Discussion}

The data collected by the teacher participants in the two different educational systems indicated that the delivered training was helpful but not adequate in addressing their overall concerns on Roma issues. Even after the training, most teachers continued to lack sufficient knowledge and confidence to work optimally with Roma children and indicated the need for further training in view of everyday classroom challenges. Consequently, further programmes for teacher professional development enhancing the intercultural dimension would need to be designed with care.

Towards this direction, consideration could be given to the five aspects for such programmes, suggested by Moliner and Lopez (2005): friendship with people from other cultures; multicultural coexistence; school coexistence and learning other cultures; intercultural 
cooperation; and respect of cultural differences. Within the context of the particular study, some of these aspects could prove particularly challenging to address. Of great importance would be the first aspect concerning beliefs, attitudes and subjective norms that refer to relationships as well as a willingness to develop friendships with those who are different. Friendship with Roma could be particularly problematic in the case of Greek-Cypriot teachers, since Roma were considered as part of the Turkish-Cypriot community, which made their acceptance even more difficult. The second and third aspect -multicultural and school coexistence- could address development of a positive predisposition towards living in the same neighbourhood and in the same schools with Roma and having social relationships with them, accepting their different customs and ways of life as means of mutual enrichment and cultural learning. Again, this aspect could be challenging in view of the segregation of Roma communities in both contexts. Regarding the last two aspects, i.e. intercultural cooperation and respect of cultural differences, participants would need to have a clear idea of Roma cultural identity and values.

In view of the aspects above, focus could be placed on three dimensions: learning about the 'other', self-awareness and empathy as well as the practical domain.

\subsection{Learning about the 'other': Awareness of Roma culture}

Firstly, this study demonstrated that the influence of the training programme, while somehow important, did not exist in isolation to the context in which teachers operated and in specific, to their experiences. Greek-Cypriot teachers, compared to their Greek colleagues, had increased needs for further training on Roma education, as they appeared less experienced with Roma. This could be attributed to the separation of the country after 1974 that alienated the population of the island by forcibly keeping the people divided to two separate communities; only since April 2003 with the arsis of travel restrictions did the Greek-Cypriots have recent interaction with Roma. On the contrary, Greek teachers more experienced in teaching Roma children were more predisposed to find the training useful, compared to their Greek-Cypriot counterparts. One could argue that in the case of teachers experienced in teaching Roma, training possibly provided a forum for sharing such experiences. However, the presumption should not be made that teachers without extensive experiences should not be offered training programmes. Rather, since training structures should accommodate different needs, training content could be tailored to teachers' prior background and channels for exchange of the wealth of participants' experiences should be established. Such an approach could address a weakness of the teaching profession which frequently, as pinpointed by Tuomi (2004), is 'not structured to easily tap into the expertise of practitioners' (p. 301).

The most compelling gain for teachers, especially inexperienced professionals, appeared to be the endorsement of the idea that they personally needed to know more about Roma as a cultural group in order to be able to teach them. Participants kept referring to the Roma as different, often highlighting a distinction between 'them' (the Roma) and 'us' (the Greek-Cypriot and the Greek teachers) and denoting a view of Roma as 'others'. Although this distinction appeared sharper in the case of Greek-Cypriot teachers (possible due to the 
reasons discussed above), teachers in both contexts repeatedly pointed to their need for more specialized training on Roma. Thus, it seems that when training programmes on Roma education fail to focus heavily on Roma history and culture and concentrate on intercultural education as a broader framework for dealing with diverse populations, participants gain a rather vague outlook, which might not be effective in supporting them dealing with Roma students, in particular. This does not imply that teachers could not benefit from general intercultural training programmes, emphasising interdependence, interconnections and interrelationships (Carignan et al., 2005) but that an acquaintance with Roma culture and history is critical.

However, as Guo et al. (2009) argue, learning about the 'other' can be superficial if in-depth issues of cultural and racialized diversity are not explored in depth. In view of the lack of teachers' confidence to deal with Roma issues, the need for training on Roma culture (highlighted above) beyond superficial information on this particular group appears urgent.

Towards this direction, action could be taken not only through training but also supporting measures. For instance, in other educational systems the lack of understanding of cultural preferences of Roma has been related to the absence of Roma staff in education services (Bhopal, 2004). Consequently, to meet teachers' need to know more about Roma, exemplary solutions could be applied. Measures, such as the presence of Roma teachers in the respective educational systems, have already been initiated in several European countries e.g. Ireland, Greece, France and the United Kindgom (Forray, 2002).

\subsection{Feelings about the 'other': Developing empathy and Self-awareness}

Cultural awareness and good intentions on the part of intercultural educators are not enough since teachers' practices do not challenge dominant power, established social hierarchies and unfair distributions of power and privilege (Gorgi, 2008). To integrate all these aspects in intercultural education programmes, it would be important for trainers to address empathy, i.e. an awareness of others' (in this case, Roma) perspectives.

Moral feelings and emotions would be fundamental in the development of teachers' capacity to perceive and to recognise the conflicts and problems the Roma may have. Putting themselves in another person's shoes (this case, Roma), feeling what the other feels, would not only be an intellectual exercise but a movement implying affection. In addition, several studies suggest that experiences with diversity and careful reflection on these experiences with the help of professional tutors can strongly influence participants' cultural awareness and acceptance of cultural differences (Taylor, 1994).

Thus, sessions for teachers to reflect on their conceptions of Roma towards intercultural competence (Jokikokko, 2005) could be included. Li and Lal (2005) also propose connections of critical reflective thinking with real-world problems of multiculturalism. As Gorgi (2008) suggests, intercultural education requires shifts of consciousness that enable us to see and react to the socio-political context that influences education theory and practice. Such shifts are not possible if self-awareness 'to challenge Eurocentric beliefs and practices and move from a position that assumes a singular, monocultural reality, to adopting a worldview that is 
respectful of multiple belief systems' (Guo et al. 2009, p. 574). To sum up, empathy and affection along with critical reflection as well as self-awareness would need to be embedded in teacher training programmes.

\subsection{Teaching the 'other': Facing problems related to professional contexts}

At another level, respondents raised the issue of relevance of professional development activity to the context of their classroom practices. Apparently, training should address the practical aspects of teaching and managing Roma children in the classroom. Training that fails to either consider the professional contexts in which teachers operate or set connections between training activities and school agendas appears meaningless. Substantive practical knowledge to examine diversity and support inclusive teaching practices is necessary (Guo et al., 2009).

Teachers' responses indicated the need for forms of training directly focused on the practical level. This need arises repeatedly in the respective literature with an abundance of studies pointing to the inefficiency of decontextualised professional development with minimal opportunities for follow-up activities. In particular, teachers should be empowered to engage Roma pupils more in class and not de-motivate them by placing lower demands upon them.

In this regard, teachers could be provided with professional development opportunities to exchange experiences beyond seminars through alternative forms of professional growth, such as action research and informal information sharing at school. Action research in particular can be applied to encourage professional culture towards an intercultural and inclusive approach (Sales et al., 2011). Again, practices in other systems could be considered. As Bhopal (2004) suggests, teachers working in ethnically mixed classes should receive special training and be supported by experts and intercultural mediators.

Finally, professional development is not the only factor that influences teaching Roma children in schools. Respondents noted lack of appropriate teaching resources as critical in their efforts to address difficulties in teaching Roma children. So, the development of respective material would enhance teachers' efforts towards Roma education.

\section{Concluding comment}

To sum up, although this particular training initiative had some impact on teachers' levels of confidence, at least in the case of Greek teachers, it is not as yet known whether it has improved teachers' levels of competencies in dealing with Roma children. Hopefully, impact on students will not take long to appear as a desired outcome on the agenda of training providers. Outcomes models (Harland \& Kinder, 1997; Teitel, 2004) point that professional development is most likely to impact classroom practices and students when certain conditions are present. Training is, undoubtedly, only one such condition. However, participating in a few workshops, as DeJaeghere and Zhang (2008) suggest, is not sufficient to achieve intercultural competence, which is a developmental construct. Since the list of areas for consideration is rather long, an investment in time and effort is needed not only to design professional development activities with care but also to accompany them with supportive measures at the local as well as the systemic level. 


\section{Acknowledgement}

The study was conducted, as part of the activities for the Comenius Mulitlateral project INSETRom (134018-2007-CY-COMENIUS-CMP, http://www.iaie.org/insetrom/), funded by the European Commission (1/12/2007 to 30/11/2009). Views expressed in this article do not reflect the views of the European Commission.

\section{References}

Agathokleous, G. (2005, December). Cultural Diversity of the Roma Students in Limassol. Paper presented at the preparatory meeting of a Comenius 2.1 project in Cyprus Pedagogical Institute, Nicosia, Cyprus.

Bhopal, K. (2004). Gypsy Travellers and Education: Changing Needs and Changing Perceptions. British Journal of Educational Studies, 52 (1), 47-64. http://dx.doi.org/10.1111/j.1467-8527.2004.00254.x

Carignan, C., Pourdavood, R., King, L., \& Feza, N. (2005). Social representations of diversity: multi/intercultural education in a South African Urban School. Intercultural Education, 16 (4), 381-393. http://dx.doi.org/10.1080/14675980500304371

Chalkiotis, D. (2000). The policy of Greek Ministry of Education for the education of Gypsies. Proceedings of the Congress 'The role of Local Self-government in the Education of Gypsies' (pp. 23-25). Athens: General Secretariat of Public Training.

Cohen, L. \& Manion, L. (1994). Research Methods in Education. London: Routledge.

DeJaeghere, J., \& Zhang, Y. (2008). Development of intercultural competence among US American teachers: professional development factors that enhance competence. Intercultural Education, 19 (3), 255-268. http://dx.doi.org/10.1080/14675980802078624

Demetriou, C., \& Trimikliniotis, N. (2007, November). The Cypriot Roma/Gypsies and the Failure of Education: Anti-Discrimination and Multiculturalism as a Post-accession Challenge. Paper presented at the conference 'The Minorities of Cyprus: Past, Present and Future', 24-25. Nicosia: Cyprus.

Dikaiou, M. (1990). Illiteracy and Tsigani Minority Children in Northern Greece: An exploration of Parents and Children Views. International Migration, XXVIII (1), 47-69. http://dx.doi.org/10.1111/j.1468-2435.1990.tb00134.x

Forray, K. (2002). Results and Problems in the Education of the Gypsy Community. European Education, 34 (4), 70-90. http://dx.doi.org/10.2753/EUE1056-4934340470

Fraser, A. (1992). The Gypsies. Oxford: Blackwell Publishers.

Gorgi, P. (2008). Good Intentions are not enough: a decolonizing intercultural education. Intercultural Education, 19 (6), 515-525. http://dx.doi.org/10.1080/14675980802568319

Gotovos, A. (2003). Education and Diversity: Questions of educational Policy. Athens: Metaihmio. 
Gotovos, A. (2004a). Teachers and cultural diversity: Teachers' representations about Gypsies. Available: http://www.uoi.gr/ROMA [October 10, 2009].

Gotovos, A. (2004b). Parents' representations about diversity: stereotypes and prejudices about Gypsies in the Greek family. Available: http://www.uoi.gr/ROMA [November 4, 2009].

Gotovos, A. (2004c). Children and cultural diversity: pupil's experiences, perceptions and attitudes against the Different. Available: http://www.uoi.gr/ROMA [November 4, 2009].

Guo, Y. Arthur, N., \& Darren L. (2009). Intercultural inquiry with pre-service teachers. Intercultural Education, 20 (6), 565-577. http://dx.doi.org/10.1080/14675980903448619

Harland, J., \& Kinder, K. (1997). Teachers' Continuing Professional Development: framing a model of outcomes. Journal of In-Service Education, 23, 71-84. http://dx.doi.org/10.1080/13674589700200005

Hatzitheodoulou-Loizidou, P., \& Symeou, L. (2003). School-family-community links for the enhancement of intercultural education: The first conclusions of an intervention program. Paper presented at the "International seminar on current practices in Global Education" of the North-South Centre of Council of Europe, October 9-11 2003, in Nicosia, Cyprus.

Iacovidou, K. (2008). Cultural difference and the politics of recognition. The case of the Roma of Cyprus. [Online] Available: http://youth-partnership.coe.int/export/sites/default/youth-partnership/documents/EKCYP/Yo uth_Policy/docs/Diversity/Iacovidou.pdf [December 20, 2009].

Jokikokko, K. (2005). Interculturally trained Finnish teachers' conceptions of diversity and intercultural competence. Intercultural Education, $16 \quad$ (1), 69-83. http://dx.doi.org/10.1080/14636310500061898

Katsikas, C., \& Politou, E. (1999). 'Out of the Classroom' the Different? Gypsies, Minorities, Repatriates, and Foreigners in the Greek Education. Athens: Gutenberg.

Kokkinakis, S.K. (1983). Social characteristics of Gypsies of Ano Liossia of Attica. Review of Social Research, 48, 110-121.

Komis, K. (1998). Gypsies: History, Demography, Culture. Athens: Ellinika Grammata.

Kyuchukov, H. (2000). Transformative education for Roma (Gypsy) children: an insider's view. Intercultural Education, $11 \quad$ 273-280. http://dx.doi.org/10.1080/14675980020002420

Labridis, E.A. (2004). Stereotype - Prejudice - Social Identity: Studying the dynamic of the social representations for the Gypsies. Athens: Gutenberg

Levinson, M.P., \& Sparkers, A.C. (2005). Gypsy children, space, and the school environment. International Journal of Qualitative Studies in Education, 18 (6), 751-772. http://dx.doi.org/10.1080/09518390500298212

Li, X., \& Lal, S. (2005). Critical reflective thinking through service-learning in multicultural 
teacher education. Intercultural Education, $16 \quad$ (3), 217-234. http://dx.doi.org/10.1080/14675980500211832

Liegeois, J.P. (1986). Gypsies: An Illustrated history. Al Sag Books.

Lydaki, A. (1998). The Gypsies in the Town: Grounding in Agia Varvara. Athens: Kastaniotis. Lydaki, A. (2000). Balame and Rom: The Gypsies of Ano Liossia. Athens: Kastaniotis.

March, A., \& Strand, E. (2003). “....spies, deserters and undesirable persons...”, the Gypsies of Cyprus, [Online] Available: http://www.domresearchcenter.com/journal/18/cyprus8.html [November 4, 2009].

Marshall, C., \& Rossman, G. (1995). Designing Qualitative Research. London: Sage.

Messing, V. (2008). Good practices addressing school integration of Roma/Gypsy children in Hungary. Intercultural Education, $19 \quad$ (5), http://dx.doi.ord/10.1080/14675980802531721

Moliner Garcia, O., \& Garcia Lopez, R. (2005). Teachers' initial training in cultural diversity in Spain: attitudes and pedagogical strategies. Intercultural Education, 16 (5), 433-442. http://dx.doi.org/10.1080/14675980500378482

Moucheli, A. (1996). Gypsies and Social Exclusion. In D. Karantinos, L. Maratou-Alibranti, \& E. Fronimou (Eds.), Dimensions of the Social Exclusion in Greece (pp. 491-525). Athens: EKKE.

Nikolaou, G. (2009). Teacher training on Roma education in Greece: a discussion about the results of INSETRom experience in two Greek schools. Intercultural Education, 20 (6), 511-521. http://dx.doi.org/10.1080/14675980903448585

Ntousas, D.V. (1991). Social discrimination in the Rom Education. Ekpaideftiki Koinotita, 14, 32-37.

Ntousas, D.V. (1997). Rom and racial discriminations: in history, in society, in culture, in education and the human rights. Athens: Gutenberg.

Pecek, M., Cuk, I., \& Lesar, I. (2008). Teachers' perceptions of the inclusion of marginalised groups. Educational Studies, 34 (3), 225-239. http://dx.doi.org/10.1080/03055690701811347

Politou, E. (1996). Gypsies and School. Antitetradia tis Ekpaidefsis, 39-40, 63-69.

Sales, A., Traver, J., \& García, R. (2011). Action research as a school-based strategy in intercultural professional development for teachers. Teaching \& Teacher Education, 27 (5), 911-919. http://dx.doi.org/10.1016/j.tate.2011.03.002

Sideri, A. (1993). Research in Gypsy's Children. In A. Kaloutsi (Ed.), Children and demographic locomotion (pp. 45-56). Athens: Ellinika Grammata

Siotou, A. (2004). Family, Gender and Age in the Gypsies Society. Available: http://195.130.114.39/ROMA [November 4, 2009]. 
Stasinos, D.P. (2004). Gypsies' Children Identity and School: Behaviors, attitudes, expectations. [Online] Available: http://195.130.114.39/ROMA (December 15, 2009).

Stratiotou, (2008). Perceptions of the Gypsies Parents of Kefalonia about the Education. Unpublished Master's Dissertation, University of Ioannina, Ioannina, Greece.

Symeou, L., Karagiorgi, Y., Roussounidou, E., \& Kaloyirou, C. (2009). Roma and their Education in Cyprus: reflections on INSETRom teacher training for Roma inclusion. Intercultural Education, 20 (6), 511-521. http://dx.doi.org/10.1080/14675980903448551

Taylor, E. (1994). A learning model for becoming interculturally competent. International $\begin{array}{lllll}\text { Journal of Intercultural } & \text { Relations, } & 18, & 389-408 .\end{array}$ http://dx.doi.org/10.1016/0147-1767(94)90039-6

Teasley, C. (2005). Ambiguous Legacy: Instituting Student Diversity at a Spanish Secondary School. Cultural Studies/Critical Methodologies, 5 (2), 206-229. http://dx.doi.org/10.1177/ 1532708605274943

Teitel, L. (2004). Two Decades of Professional Development School Development in the United States: What Have We Learned? Where Do We Go from Here? Journal of In-Service Education, 30 (3), 401-416. http://dx.doi.org/10.1080/13674580400200335

Terzopoulou, M., \& Georgiou, G. (1996). The Gypsies in Greece: History - Culture. Athens: Ministry of National Education and Religions.

Trentin, R., Monaci, M., De Lumèc, F., \& Zanon, O. (2006). Scholastic Integration of Gypsies in Italy Teachers' Attitudes and Experience. School Psychology International, 27 (1), 79-103. http://dx.doi.org/ 10.1177/0143034306062816

Trimikliniotis, N. (2007). Report on Measures to Combat Discrimination Directives 2000/43/EC and 2000/78/EC: Country Report. [Online] Available: http://ec.europa.eu/employment_social/fundamental_rights/pdf/legnet/cyrep07_en.pdf (November 4, 2009).

Tuomi, M.T. (2004). Planning teachers' professional development for global education. Intercultural Education, 15 (3), 295-305. http://dx.doi.org/10.1080/1467598042000262581

UNOPS (2004). Educational Needs of Turkish-Speaking Children in Limassol.

Vasileiadou, M. (2000). Analysis of Research Data. Proceedings of the Congress 'The role of Local Self-government in the Education of Gypsies' (pp. 58-67). Athens: General Secretariat of Public Training.

Vasileiadou, M., \& Pavli-Kore, M. (1998). The Gypsies Education in Greece. Athens: Ministry of National Education and Religions.

Vaxevanoglou, A. (2001). Greek Gypsies outcasts and heads of the family. Athens: Alexandreia. 


\section{Copyright Disclaimer}

Copyright reserved by the author(s).

This article is an open-access article distributed under the terms and conditions of the Creative Commons Attribution license (http://creativecommons.org/licenses/by/3.0/). 